\title{
Design and Applications of Protein Epitope Mimetics
}

\author{
John A. Robinson*
}

\begin{abstract}
Macromolecular structures represent an interesting starting point for the design and synthesis of smallmolecule mimetics of surface epitopes that mediate protein-protein and protein-nucleic acid interactions. The resulting protein epitope mimetics (PEMs) provide a source of new biologically active molecules that are useful as biomolecular probes in chemical biology, as well as novel drug or vaccine candidates. This is illustrated here through studies on PEMs as synthetic vaccine candidates targeting the malaria parasite and the human immunodeficiency virus type-1 (HIV-1). In addition, various folded PEMs with $\beta$-hairpin structures have been designed that target protein-protein and protein-nucleic acid interactions, as well as others that interact with cellular receptors such as CXCR4 and the bacterial outer membrane protein LptD. In this last example, the PEMs possess a novel antibiotic activity that has so far not been observed with traditional small synthetic molecules or natural products.
\end{abstract}

Keywords: Antibiotic $\cdot$ Peptide $\cdot$ Peptidomimetic $\cdot$ Protein epitope mimetics $\cdot$ Vaccine

\section{Introduction}

Mimicry of the three-dimensional (3D) surface features of proteins important for function in smaller synthetic molecules called Protein Epitope Mimetics (PEMs) - has grown in importance in recent years. This area of chemical biology is being driven forward rapidly by advances in genomics and proteomics, as well as highthroughput structural biology. Efforts to design and synthesize PEMs frequently leads to novel organic molecules, peptidomimetics and foldamers, not found in natural products or traditional small druglike molecules. This opens the prospect of uncovering new biologically active molecules that might be useful tools in efforts to understand biological molecular recognition, in the development of novel biomolecular probes, as well as novel drug or vaccine candidates.

Structural information about how proteins interact with other macromolecules

\footnotetext{
${ }^{*}$ Correspondence: Prof. J. A. Robinson

Chemistry Department

University of Zurich

Winterthurerstrasse 190

$\mathrm{CH}-8057$ Zurich

Tel.: +41446354242

E-mail: robinson@oci.uzh.ch
}

provides a rational basis for PEM design. For example, many macromolecular interactions are mediated by elements of secondary structure on the surface of proteins. Synthetic molecules that mimic these folded structures may then be useful inhibitors of protein-protein and protein-nucleic acid interactions. In addition, structural information on the mechanisms of recognition by antibodies of epitopes on pathogen-derived protective antigens opens new possibilities for applying PEMs in synthetic vaccine design. ${ }^{[1]}$

Considerable scientific challenges remain, however, in transforming 3D structural information from the protein data bank (PDB) into new PEMs with appropriate chemical and biological properties. Mutagenesis experiments can reveal energetically important hot spots at proteinprotein interfaces. ${ }^{[2]}$ However, the internal dynamics of proteins, which can lead to structural changes over diverse time-scales, are more difficult to access experimentally, and yet exert a powerful influence upon binding affinity, and in ways that are frequently not obvious from a single ground state crystal structure. ${ }^{[3]}$ Notwithstanding these mechanistic problems, important progress in PEM design has been made by focusing on protein hot-spots and in optimizing surface complementarity upon binding to a macromolecular target.

\section{Design of $\beta$-Hairpin Mimetics}

$\beta$-Hairpin surface loops are found in many proteins, where they are frequently involved in macromolecular recognition. $\beta$-Hairpin loops contain two antiparallel $\beta$-strands with an intervening turn segment (Fig. 1). Many subtle variations can occur in the backbone conformation of $\beta$-hairpin loops in folded proteins, depending upon the loop length and patterns of hydrogenbonding interactions. ${ }^{[4]} \beta$-Hairpin mimetics can be designed by taking the hairpin loop from a folded protein and transplanting this onto a suitable semi-rigid template designed to stabilize $\beta$-hairpin backbone conformations. ${ }^{[5]}$ For example, the dipeptide D-Pro-L-Pro, which (importantly) adopts a very stable type-II' $\beta$-turn, ${ }^{[6]}$ is ideal for nucleating the preferred righthanded twist often seen between adjacent antiparallel $\beta$-strands in proteins. The approach was first used in the design of mimetics of hairpin loops in the receptor for IFN $\gamma$ and in CDR loops from IgG antibodies, as illustrated in Fig. 1. ${ }^{[7]}$ When transplanting a $\beta$-hairpin loop from a known protein structure onto this template, the $\mathrm{N}$ - and $\mathrm{C}$-terminal loop residues adjacent to the template will be forced into a crossstrand hydrogen bonding geometry (Fig. 1). The template then functions to stabilize hairpin conformations and to constrain the cross-strand hydrogen-bonding register in the loop.

An efficient method of synthesizing such $\beta$-hairpin mimetics has been established, in which a linear peptide precursor is assembled using solid-phase Fmocchemistry with subsequent cyclization and deprotection in solution. ${ }^{[8]}$ This process is very efficient and can be run in parallel, and is therefore ideal for the production of libraries of structurally related hairpin mimetics. Proteinogenic and non-proteinogenic amino acids can be used for the assembly process, and the resulting librar- 


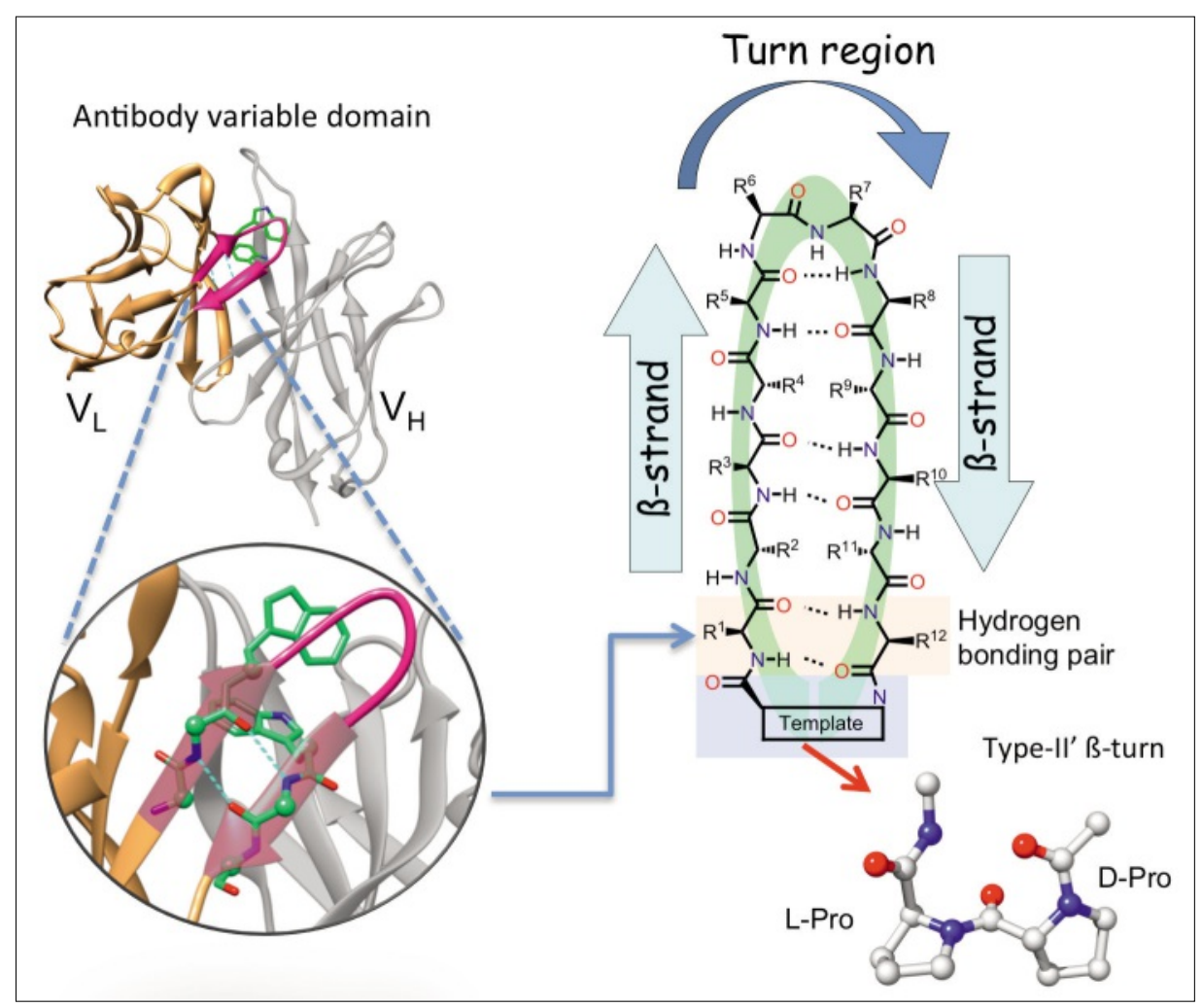

Fig. 1. Conformationally constrained $\beta$-hairpin mimetics can be designed by transplanting the hairpin sequence from the protein of interest onto a suitable hairpin-stabilizing template (e.g. DPro-L-Pro, see text).

ies can then be very useful to screen and optimize structure and biological properties. This process forms the basis of the PEM-technology, which has been commercialized by Polyphor AG and applied to challenging pharmaceutical targets such as protein-protein interaction inhibitors that have proven difficult to address using traditional small drug-like molecules. ${ }^{[9]}$

Various applications of $\beta$-hairpin mimetics have been investigated including molecules that bind to the Fc fragment of IgGs, ${ }^{[10]}$ mimetics that bind to and inhibit serine proteases such as trypsin, ${ }^{[11]}$ and mimetics that bind to RNA targets such as the TAR and RRE RNA from HIV-1. ${ }^{[12]}$ Folded RNA segments represent particularly interesting targets for $\beta$-hairpin mimetics. Recently, $\beta$-hairpin mimics of the Tat protein were discovered that are $\mathrm{pM}$ inhibitors of the Tat-TAR interaction and discriminate between even closely related RNAs. ${ }^{[13]}$ Interestingly, the structure of TAR RNA bound to one mimetic has a quite different conformation to that seen in the RNA with no bound ligand, or bound to argininamide. ${ }^{[12 e, 14]}$ The complex internal dynamics of the TAR RNA seems to be particularly important in adapting and binding to the $\beta$-hairpin-shaped peptidomimetics. One mimetic has been shown to inhibit HIV-1 infection in whole cells. The mimetic is a nanomolar inhibitor of cellular HIV-1 replication, inhibiting replication in primary lymphocytes of a wide such as the chemokine receptor CXCR4 on lymphocytes, ${ }^{[18]}$ and the outer membrane translocon LptD in Gram-negative bacteria (see below).[19] PEMs targeting CXCR4 are very potent and selective inhibitors of this G-protein coupled receptor (GPCR), which in humans promotes chemotaxis in leukocytes, progenitor cell migration, and embryonic development of the cardiovascular, hematopoietic and central nervous systems. CXCR4 has also been associated with multiple types of cancers, where its overexpression/activation promotes metastasis, angiogenesis and tumor growth/survival. CXCR4 is also one of the co-receptors used by HIV-1 to gain entry into lymphocytes. ${ }^{[20]}$ Molecules that antagonize CXCR4 are therefore potentially useful to induce mobilization of hematopoietic stem cells from the bone marrow to the periphery, for example, for stem cell transplantation, as well as for anti-cancer and anti-HIV activity. A recent crystal structure illustrates in atomic detail how one $\beta$-hairpin peptide interacts with CXCR4. ${ }^{[21]}$

\section{Synthetic Vaccine Design}

Conformationally constrained PEMs are also likely to find important applications in synthetic vaccine design.[22] Of special interest are epitopes on the surface of invading microorganisms that are recognized by antibodies that protect against infection - so-called protective or neutralizing antibodies. There is a rapidly growing number of crystal structures in the PDB of neutralizing antibody Fab fragments bound to their cognate pathogen-derived antigens. ${ }^{[23]}$ Such crystal structures reveal the folded epitope used to elicit a protective humoral immune response. One challenge is to design synthetic molecules that mimic these folded structures and that can be used to elicit a protective immune response against the pathogen. ${ }^{[24]} \mathrm{A}$ further challenge is to find a suitable method to

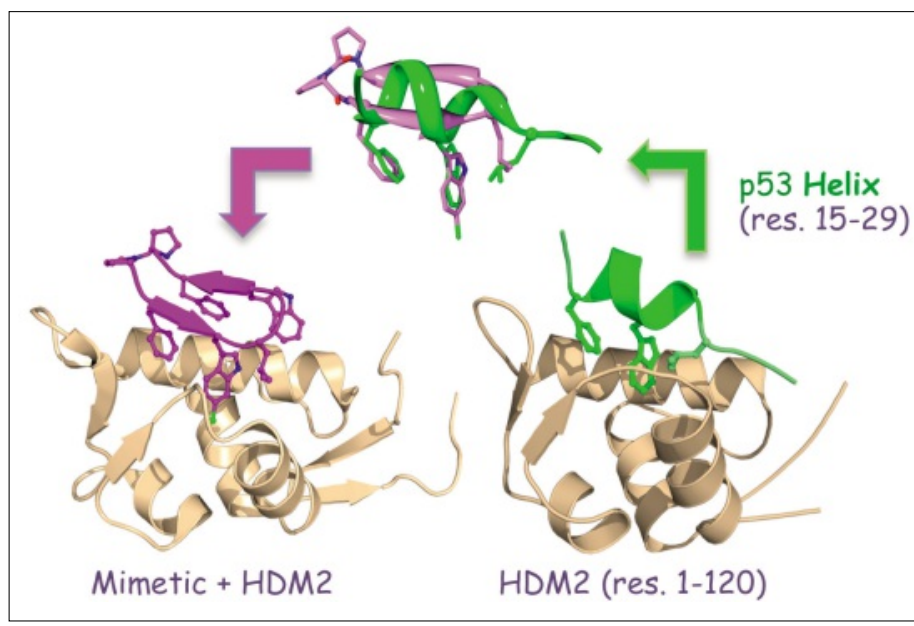

Fig. 2. Using a $\beta$-hairpin to mimic an $\alpha$-helix. In this case, the helical epitope seen (right) in the crystal structure of a p53-derived peptide bound to a domain of HDM2 (PDB 1YCR), ${ }^{[15]}$ is converted into a $\beta$-hairpin PEM that binds to HDM2 (left) with nanomolar affinity (PDB 2AXI). [16a,16b,17] 
deliver the epitope mimetics to the immune system, so that a strong specific (and protective) immune response is elicited in a diverse human population. Here the engineering of nanoparticles holds great promise for the development of new immunomodulatory agents. ${ }^{[25]}$ Two examples from recent work illustrate how these challenges might be addressed.

Our efforts to design a synthetic malaria vaccine focused initially upon the so-called circumsporozoite (CS) protein, an immunodominant protective antigen on the surface of the sporozoite stage of Plasmodium falciparum, carried by live mosquitoes. ${ }^{[26]}$ The central region of this membrane-anchored CS protein contains a $(\mathrm{NPNA})_{\approx 37}$ repeat region, which is highly immunogenic. Early attempts to exploit this repeat region in a clinical trial using a linear (NANP) ${ }_{3}$ peptide conjugated to tetanus toxin in alum, ${ }^{[27]}$ gave disappointing results. In our approach, sequential rounds of epitope design, synthesis and testing were followed, to identify vaccine candidates that elicit primarily or exclusively antibodies that contribute to protection against sporozoite invasion of liver cells.

The NPNA repeat has long been known to favor $\beta$-turn conformations in solution. ${ }^{[28]}$ Indeed, a crystal structure of the peptide Ac-ANPNA-NH $\mathrm{N}_{2}$ revealed the NPNA motif in a type-I $\beta$-turn conformation (Fig. 3). ${ }^{[29]}$ However, it is still unclear how such $\beta$-turns might propagate in the CS protein, containing multiple tandemly linked copies of the NPNA motif. It proved possible to stabilize $\beta$-turn conformations in linear NPNA-repeats by substituting Pro for $\alpha$-methyl-proline. [31] Further rounds of optimization, however, including studies of template-linked macrocyclic peptides, ${ }^{[32]}$ led to a constrained derivative called UK40 (Fig. 3), which proved to have structural and antigenic similarity to the repeat region of the native $\mathrm{CS}$ protein. ${ }^{[30]}$ For delivery, this mimetic was coupled to a phospholipid (to give UK39) and incorporated into reconstituted influenza viruslike particles (also called virosomes, or immunopotentiating reconstituted influenza virosomes (IRIVs)). ${ }^{[30,32 i]}$ IRIVs are spherical, unilamellar enveloped virus-like particles, prepared by detergent removal from a mixture of natural and synthetic phospholipid and influenza surface glycoproteins. Upon reconstitution from lipids, influenza proteins, and the lipo-peptide antigen, the CS epitope mimetic should be displayed on the surface of the IRIV nanoparticles where it can be recognized by B cells. In this way, delivery of UK39 to mice and rabbits elicited high titres of sporozoite cross-reactive antibodies that inhibit invasion of hepatocytes by $P$. falciparum sporozoites. ${ }^{[30]}$

This approach was predicated upon the

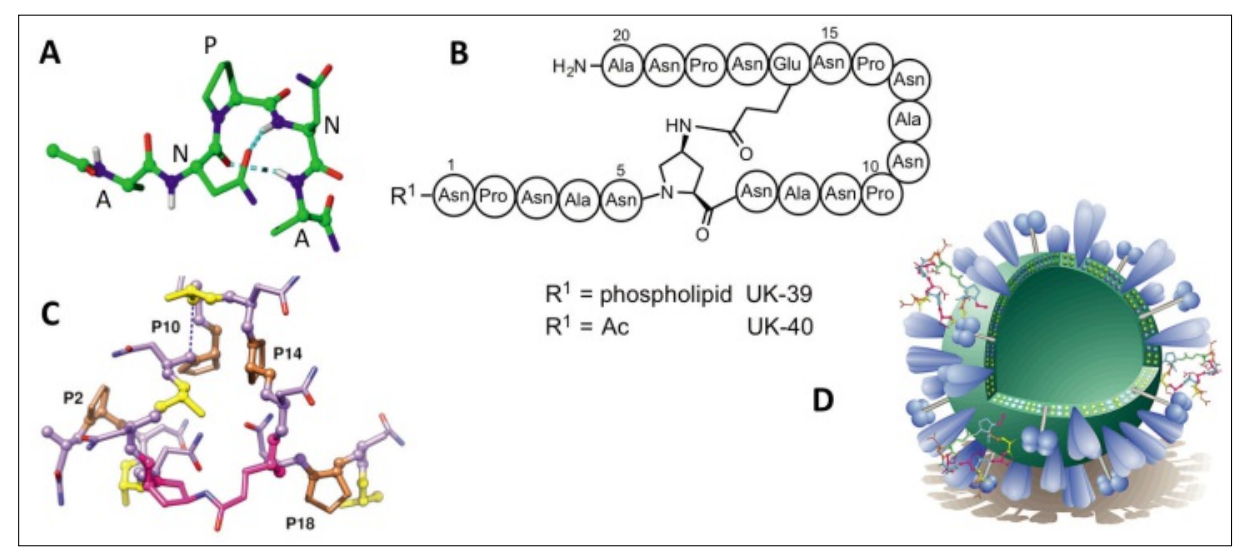

Fig. 3. A malaria vaccine based upon a constrained peptide from the NPNA repeats in the CS protein. A, Crystal structure of Ac-ANPNA- $\mathrm{NH}_{2}{ }^{[29]} \mathbf{B}$, The mimetics UK39 and UK40. C, Average NMR solution structure of the mimetic UK40. ${ }^{[30]} \mathbf{D}$, Cartoon representing the display of an epitope mimetic on the surface of IRIVs. Influenza glycoproteins are represented in blue, the membrane in green.

idea that several synthetic antigens, mimicking epitopes on different stages of the $P$. falicparum life cycle, might be combined to form a multicomponent, multi-stage vaccine. As a next step, a second lipopeptide was developed to elicit antibodies against the apical membrane antigen 1 (AMA-1), a membrane protein that is located within the apical complex of the merozoite surface of the liver-stage parasite, and which is essential for invasion of erythrocytes. ${ }^{[33]}$ A cyclized synthetic peptide (called AMA49-C1 as a phospholipid conjugate), based upon the semi-conserved loop I of domain III, was identified and shown to induce asexual blood-stage parasite growth inhibitory antibodies using the IRIV delivery system. ${ }^{[33 a]}$ Additional mimetics were also prepared and tested based on epitopes in the merozoite proteins MSP-1, MSP-3 and serine-repeat antigen 5. ${ }^{[34]}$

In several phase I/II clinical studies conducted by Pevion AG in collaboration with the Swiss Tropical and Public Health Institute, the virosomally formulated UK39 and AMA49-C1 vaccine was found to be well tolerated, and both components elicited strong specific antibody responses in all immunized volunteers. ${ }^{[35]}$ A promising observation made during clinical trials in Africa was that the incidence of clinical malaria episodes in children receiving the vaccine was half the rate of the control children. ${ }^{[35 \mathrm{~d}]}$ These encouraging results suggest that further development of this approach to a multivalent malaria peptide vaccine may be worthwhile.

In a second example, a different nanoparticle delivery vehicle is exemplified, made from components totally of synthetic origin. The Synthetic Virus-Like Particle (SVLP) delivery system makes use of designed synthetic lipopeptide building blocks that spontaneously self-assemble in aqueous buffers into 20-30 nm nanoparticles. ${ }^{[36]}$ The lipopeptide building blocks contain a peptidic parallel trimeric coiledcoil motif, fused to a CD4 ${ }^{+}$T-helper epitope (Fig. 4). The lipid portion can be a bacterial TLR ligand such as Pam ${ }_{2}$ Cys or Pam ${ }_{3}$ Cys, which is conjugated to one terminus of the peptide chain. The other terminus can be exploited to attach a protective (or neutralizing) B-cell epitope, in the form of a small synthetic epitope mimetic or a recombinant protein. The self-assembly process in aqueous buffer is driven by formation of parallel trimeric helical bundles via the coiled coil motif and then by association of the helical bundles into a nanoparticle, with the lipid chains sequestered from solvent in the core of the particle. An array of about $70-80$ copies of the B-cell epitope are then displayed over the surface of the nanoparticle. ${ }^{[36 a-c]}$ Dendritic cells internalize SVLPs rapidly using various endocytic routes, in particular, by caveolin-independent lipid raft-mediated macropinocytosis. [36e] Inside dendritic cells, the lipopeptide constituents are processed more slowly by proteolysis. Several studies have shown already that the SVLP-delivery system can generate strong epitope-specific immune responses in laboratory animals without need for external adjuvants. One application is described below, focusing on the V3 loop in the HIV-1 envelope glycoprotein gp120.

The $\beta$-hairpin V3 loop is a highly immunogenic region of the HIV-1 envelope glycoprotein gp120 that becomes exposed on the viral surface after binding to the primary receptor CD4 on target cells. ${ }^{[38]}$ Several crystal structures are now available of Fab fragments from neutralizing antibodies bound to peptides derived from the V3 loop, including one of the $\mathrm{mAb}$ F425-B4e8.[37] The linear V3 peptide is flexible in free solution, but a constrained V3 loop mimetic was prepared[37] by affixing the loop sequence onto the D-Pro-L-Pro template.[35d,39] ${ }^{1} \mathrm{H}-\mathrm{NMR}$ studies revealed 


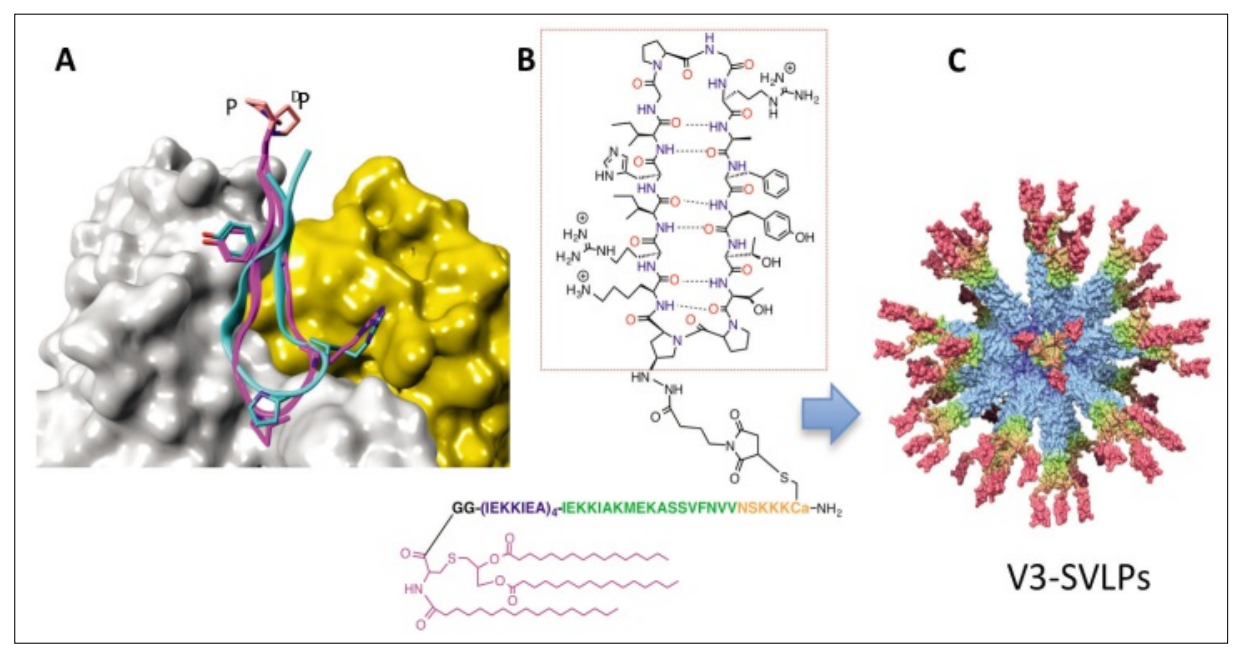

Fig. 4. Design of an HIV-1 V3 loop mimetic. A, Crystal structure of a V3-derived linear peptide (cyan) bound to the Fab fragment of mAb F425-B4e8 (gray/yellow surface) (PDB 2QSC). ${ }^{\left[{ }^{[3]}\right.}$ The solution structure of a V3 loop mimetic (purple, with D-Pro-L-Pro template (orange) at the top) is shown superimposed on the bound linear peptide. ${ }^{[360]} \mathbf{B}$, Conjugation of the V3 loop mimetic (boxed) with a lipopeptide building block. This lipopeptide assembles spontaneously into SVLPs in aqueous buffer. C, A computer model is shown of an SVLP particle with multiple V3 epitope mimetics (red) displayed on the surface of the nanoparticle. a very close structural similarity between this mimetic and the $\mathrm{V} 3$ peptide bound to the F425-B4e8 antibody. ${ }^{[36 d]}$

To study immune responses, this V3 loop mimetic was linked to the SVLP lipopeptide building blocks through a Cys residue placed near the C-terminus of the peptide chain. Extensive biophysical studies provided strong evidence for a computer model of the resulting SVLPs, shown in Fig. 4, with multi-valent display of the epitope mimetics on the surface of the nanoparticle. These V3-SVLPs proved to be highly immunogenic in rabbits, where high titers of $\operatorname{IgG}$ antibodies specific for the V3-mimetic were observed. Moreover, some of the antibodies bind specifically to recombinant gp120 by ELISA and showed HIV-1 neutralizing activity in whole cell infection assays. [36d]

These results illustrate a chemistrybased and structure-driven approach to vaccine discovery, which may allow the targeting both infectious and chronic human diseases. The SVLP technology and its use in synthetic vaccine design is now being pursued by the company Virometix AG.

\section{Discovery of the $\beta$-Hairpin Antibiotics}

Naturally occurring cationic antimicrobial peptides (CAPs) play key roles in the innate immune systems in many different organisms, where they typically provide a first line of defense against viral and bacterial infection. ${ }^{[40]}$ Many CAPs show broadspectrum antimicrobial activity in the micromolar range, typically by causing lysis design of many new vaccine candidates of microbial cell membranes. ${ }^{[40 b]}$ This lytic action, however, can also occur with human cells (e.g. red blood cells), albeit at higher concentrations.

One group of CAPs, including the protegrins, polyphemusins, tachyplesin, arenicin and $\Theta$-defensin, possess $\beta$-hairpin structures stabilized by disulfide bridges. ${ }^{[40]}$ We set out to investigate whether structurally related $\beta$-hairpin PEMs could be developed that retain good antimicrobial activity, but with a reduced lytic (toxic) effect on human red blood cells. Macrocyclic peptidomimetics were designed using the D-Pro-L-Pro template to stabilize folded $\beta$-hairpin structures. In this way, peptides were discovered that indeed possess broadspectrum antimicrobial activity in the low micromolar range, comparable to that seen with protegrin I, but with much reduced lytic activity against human red blood cells. [41] Attempts to improve further the antimi- crobial activity, by an iterative process of library synthesis and screening, led to the discovery of cyclic peptidomimetics with a novel type of antimicrobial activity. ${ }^{[19 a]}$ The most active congener was the cyclic peptide L27-11 (Fig. 5), which is active in the low nanomolar range against Gramnegative Pseudomonas sp. Interestingly, the enantiomeric form shows no activity (MIC $\geq 32 \mu \mathrm{g} / \mathrm{ml}$ ), which already suggested a highly enantioselective interaction with a chiral target, rather than a non-stereoselective interaction with lipid chains of the cell membrane, which is typical of many CAPs. NMR studies showed that L27-11 indeed adopts $\beta$-hairpin conformations in solution, and that the $\beta$-hairpin structure is important for antimicrobial activity. ${ }^{[42]}$

The mechanism of action of these novel antibiotics is of great interest. L27-11 shows no membranolytic activity. The target of the antibiotic was revealed by two complementary approaches, namely, photoaffinity labeling experiments and a genetic screen for resistance determinants in $P$. aeruginosa. It is notable that these two quite different approaches pointed to the same $\beta$-barrel outer membrane (OM) protein, LptD, as the likely target. Important progress in understanding the function of LptD in E. coli and related Gram-negative bacteria has been made in recent years. ${ }^{[43]}$ $\mathrm{LptD}$ is present in the OM of most Gramnegative bacteria in a complex with the lipoprotein LptE.[44] The LptD/E complex has an essential function in the biogenesis of the outer cell membrane.

The inner membrane (IM) of Gramnegative bacteria is a phospholipid bilayer, however, the $\mathrm{OM}$ is an asymmetric bilayer composed of phospholipids in the inner leaflet and complex glycolipid lipopolysaccharide (LPS) molecules in the outer leaflet (Fig. 5). This asymmetric OM does not form spontaneously, but rather requires dedicated machinery for assembly during cell growth. New LPS molecules are as-

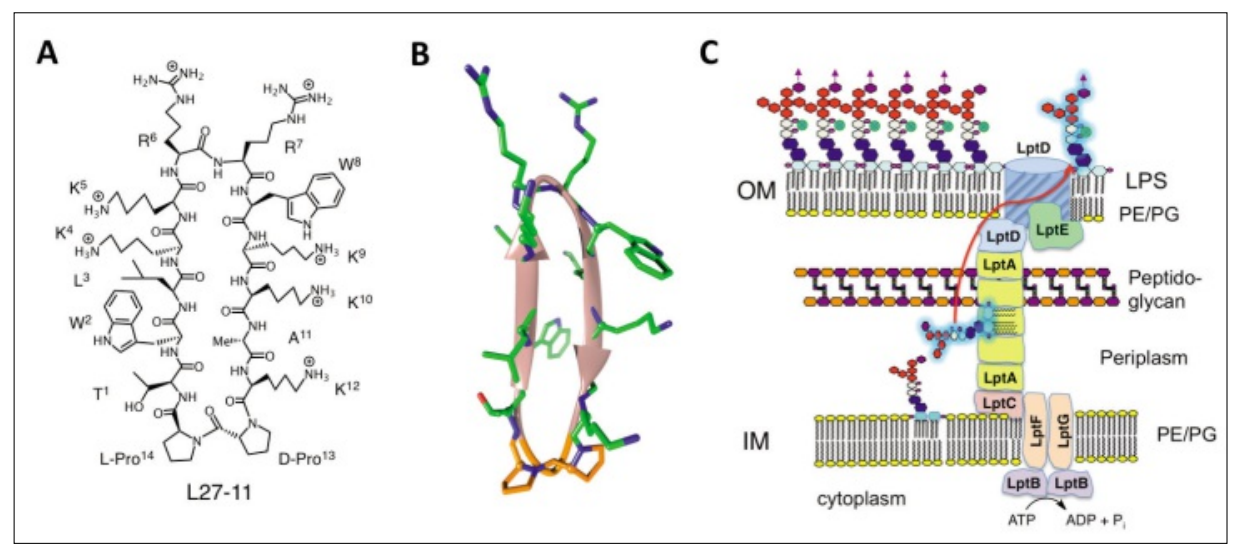

Fig. 5. A, The $\beta$-hairpin antibiotic L27-11 that interacts with LptD. B, NMR solution structure of L27-11. ${ }^{[42]} \mathbf{C}$, The double membrane of Gram-negative bacteria. LptD is an OM protein that is required for translocation of LPS molecules from the periplasm to the cell surface during cell wall biogenesis (see text). 
sembled in the cytoplasm and at the IM, are then extracted from the IM, transported across the periplasm, and then translocated from the periplasmic side to the outer surface of the OM. Seven essential Lpt (lipopolysaccharide transport) proteins (LptA-G) are known to mediate this transport process. ${ }^{[43 \mathrm{~b}, 45]}$ The LptD/E complex has the important function of translocating LPS from the periplasm to the outer cell surface. Upon exposure to L27-11, defects in OM structure were revealed by transmission electron microscopy within $P$. aeruginosa cells. ${ }^{[19 a]}$ This and other experimental evidence support the hypothesis that the antibiotic, by interaction with LptD, inhibits LPS transport to the cell surface, leading to disruption of OM biogenesis. [19b] So far no other small molecules or natural products are known that target the essential LptD/E translocon in the OM of Gram-negative bacteria.

Given the potency of the antibiotic against $P$. aeruginosa, and its novel mechanism of action, the molecule could be very valuable in the treatment of infections caused by this dangerous human pathogen. $P$. aeruginosa is one of the seven socalled ESKAPE pathogens (Enterococcus faecium, Staphylococcus aureus, Klebsiella pneumoniae, Acinetobacter baumanii, Pseudomonas aeruginosa and Enterobacter spp.), a selection of antibiotic-resistant bacteria highlighted by the Infectious Diseases Society of America (IDSA) that increasingly cause difficult-totreat infections in hospitals and the wider community. ${ }^{[46]}$ The company Polyphor AG has now developed related PEMs such as POL7001, with greatly improved stability in human plasma. ${ }^{[19 a]}$ In addition, a clinical candidate called POL7080 with optimized ADMET properties has been identified, which has recently completed successfully a human phase I clinical study. ${ }^{[47]}$ In future work, it will be fascinating to see whether related $\beta$-hairpin antibiotics can be found that target other essential $\beta$-barrel OM proteins, such as LptD in the other Gramnegative bacteria highlighted by the ISDA.

\section{Acknowledgements}

Special thanks go to all the talented students and post-docs who carried out the research at UZH described above, as well as Annelies Meier for outstanding technical support. Special thanks also go to Dr. Daniel Obrecht and the rest of the PEM team at Polyphor AG; to Dr. Arin Ghasparian at Virometix AG; to Prof. Gerd Pluschke at the Swiss Tropical Institute; to Prof. Gabriele Varani, University of Washington, USA; and to Profs. Alexandra Trkola and Prof. Leo Eberl at UZH for collaborations.

Received: September 12, 2013

[1] P. R. Dormitzer, G. Grandi, R. Rappuoli, Nat. Rev. Microbiol. 2012, 10, 807.
[2] a) T. Clackson, J. A. Wells, Science 1995, 267, 383; b) W. L. DeLano, Curr. Opin. Struct. Biol. 2002, 12, 14; c) D. Reichmann, O. Rahat, M. Cohen, H. Neuvirth, G. Schreiber, Curr. Opin. Struct. Biol. 2007, 17, 67.

[3] K. Henzler-Wildman, D. Kern, Nature 2007, $450,964$.

[4] a) K. Gunasekaran, C. Ramakrishnan, P. Balaram, Prot. Engineer. 1997, 10, 1131; b) B. L. Sibanda, T. L. Blundell, J. M. Thornton, $J$ Mol. Biol. 1989, 206, 759; c) B. L. Sibanda, J. M. Thornton, Nature 1985, 316, 170.

[5] J. A. Robinson, Acc. Chem. Res. 2008, 41, 1278.

[6] a) C. M. Nair, M. Vijayan, Y. V. Venkatachalapathi, P. Balaram, J. Chem. Soc. Chem. Comm 1979, 1183; b) J. W. Bean, K. D. Kopple, C. E. Peishoff, J. Am. Chem. Soc. 1992, 114,5328 ; c) D. K. Chalmers, G. R. Marshall, J. Am. Chem. Soc. 1995, 117, 5927.

[7] a) J. Späth, F. Stuart, L. Jiang, J. A. Robinson, Helv. Chim. Acta 1998, 81, 1726; b) M. Favre, K. Moehle, L. Jiang, B. Bfeiffer, J. A. Robinson, J. Am. Chem. Soc. 1999, 121, 2679.

[8] L. Jiang, K. Moehle, B. Dhanapal, D. Obrecht, J. A. Robinson, Helv. Chim. Acta 2000, 83, 3097.

[9] a) D. Obrecht, E. Chevalier, K. Moehle, J. A Robinson, Drug Discov. Today: Technol. 2012, 9, e63; b) J. A. Robinson, S. J. DeMarco, F. O. Gombert, K. Moehle, D. Obrecht, Drug Disc. Today 2008, 13, 944

[10] R. L. A. Dias, R. Fasan, K. Moehle, A. Renard, D. Obrecht, J. A. Robinson, J. Am. Chem. Soc. 2006, 128,2726

[11] A. Descours, K. Moehle, A. Renard, J. A. Robinson, ChemBioChem 2002, 3, 318 .

[12] a) Z. Athanassiou, R. L. A. Dias, K. Moehle, N. Dobson, G. Varani, J. A. Robinson, J. Am. Chem. Soc. 2004, 126, 6906; b) Z. Athanassiou, K. Patora, R. L. A. Dias, K. Moehle, J. A. Robinson, G. Varani, Biochemistry 2007, 46, 741; c) M. F. Bardaro, Z. Shanjani, K. PatoraKomisarska, J. A. Robinson, G. Varani, Nucl. Acids Res. 2009, 37, 1529; d) A. Davidson, T. C. Leeper, Z. Athanassiou, K. Patora, J. Karn, J. A. Robinson, G. Varani, Proc. Natl. Acad. Sci. USA 2009, 106, 11931; e) A. Davidson, K. Patora-Komisarska, J. A. Robinson, G. Varani, Nucl. Acids Res. 2011, 39, 248; f) M. S. Lalonde, M. A. Lobritz, A. Ratcliff, M. Chamanian, Z. Athanassiou, M. Tyagi, J. L. Wong, J. A. Robinson, J. Karn, G. Varani, E. J. Arts, Plos Pathogens 2011, 7, e1002038; g) T. C. Leeper, Z. Athanassiou, R. L. A. Dias, J. A. Robinson, G. Varani, Biochemistry 2005, 44, 12362; h) K. Moehle, Z. Athanassiou, K. Patora, A. Davidson, G. Varani, J. A. Robinson, Angew. Chem. Int. Ed. 2007, 46, 9101.

[13] G. Varani, J. Biomol. Struct. Dynam. 2013, 31, 131.

[14] a) A. S. Brodsky, J. R. Williamson, J. Mol. Biol. 1997, 267, 624; b) F. Aboul-ela, J. Karn, G. Varani, J. Mol. Biol. 1995, 253, 313.

[15] P. H. Kussie, S. Gorina, V. Marechal, B. Elenbaas, J. Moreau, A. J. Levine, N. P. Pavletich, Science 1996, 274, 948.

[16] a) R. Fasan, R. L. A. Dias, K. Moehle, O. Zerbe, D. Obrecht, P. R. E. Mittl, M. G. Grutter, J. A. Robinson, Chembiochem 2006, 7, 515; b) R. Fasan, R. L. A. Dias, K. Moehle, O. Zerbe, J. W. Vrijbloed, D. Obrecht, J. A. Robinson, Angew. Chem. Int. Ed. 2004, 43, 2109; c) M. Seitz, P. Rusert, K. Moehle, A. Trkola, J. A. Robinson, Chem. Commun. 2010, 46, 7754 .

[17] A. Grässlin, C. Amoreira, K. K. Baldridge, J. A. Robinson, ChemBioChem 2009, 10, 1360.

[18] a) S. J. DeMarco, H. Henze, A. Lederer, K. Moehle, R. Mukherjee, B. Romagnoli, J. A. Robinson, F. Brianza, F. O. Gombert, S. Lociuro, C. Ludin, J. W. Vrijbloed, J. Zumbrunn, J. P. Obrecht, D. Obrecht, V. Brondani, F. Hamy,
T. Klimkait, Bioorg. Med. Chem. 2006, 14, 8396; b) A. Lederer, S. J. DeMarco, H. Henze, B. Romagnoli, R. Mukherjee, J. Zumbrunn, F. Brianza, F. O. Gombert, C. Ludin, J. W. Vrijbloed, J.-P. Obrecht, S. Lociuro, V. Brondani, F. Hamy, T. Klimkait, K. Moehle, J. A. Robinson, D. Obrecht, Chimia 2007, 61, 147.

[19] a) N. Srinivas, P. Jetter, B. J. Ueberbacher, M. Werneburg, K. Zerbe, J. Steinmann, B. Van der Meijden, F. Bernardini, A. Lederer, R. L. A. Dias, P. E. Misson, H. Henze, J. Zumbrunn, F. O. Gombert, D. Obrecht, P. Hunziker, S. Schauer, U. Ziegler, A. Kach, L. Eberl, K. Riedel, S. J. DeMarco, J. A. Robinson, Science 2010, 327, 1010; b) M. Werneburg, K. Zerbe, M. Juhas, L. Bigler, U. Stalder, A. Kaech, U. Ziegler, D. Obrecht, L. Eberl, J. A. Robinson, ChemBiochem 2012, 13, 1767.

[20] W.-T. Choi, S. Duggineni, Y. Xu, Z. Huang, J. An, J. Med. Chem. 2011, 55, 977.

[21] B. Wu, E. Y. T. Chien, C. D. Mol, G. Fenalti, W. Liu, V. Katritch, R. Abagyan, A. Brooun, P. Wells, F. C. Bi, D. J. Hamel, P. Kuhn, T. M. Handel, V. Cherezov, R. C. Stevens, Science 2010, 330, 1066

[22] J. A. Robinson, J. Pept. Sci. 2013, 19, 127.

[23] D. Corti, A. Lanzavecchia, Annu. Rev. Immunol. 2013, 31, 705

[24] D. W. Kulp, W. R. Schief, Curr. Opin. Virol. 2013, 3, 322

[25] D. M. Smith, J. K. Simon, J. R. Baker Jr, Nat. Rev. Immunol. 2013, 13, 592.

[26] a) R. J. Schwenk, T. L. Richie, Trends Parasitol. 2011, 27, 306; b) K. Arun Kumar, G.-i. Sano, S. Boscardin, R. S. Nussenzweig, M. C. Nussenzweig, F. Zavala, V. Nussenzweig, Nature 2006, 444, 937.

[27] D. A. Herrington, D. F. Clyde, G. Losonsky, M. Cortesia, J. R. Murphy, J. Davis, S. Baqar, A. M. Felix, E. P. Heimer, D. Gillessen, E. Nardin, R. S. Nussenzweig, V. Nussenzweig, M. R. Hollingdale, M. M. Levine, Nature 1987, 328, 257.

[28] H. J. Dyson, A. C. Satterthwait, R. A. Lerner, P. E. Wright, Biochemistry 1990, 29, 7828

[29] A. Ghasparian, K. Moehle, A. Linden, J. A. Robinson, Chem. Commun. 2006, 174.

[30] S. L. Okitsu, U. Kienzl, K. Moehle, O. Silvie, E. Peduzzi, M. S. Mueller, R. W. Sauerwein, H. Matile, R. Zurbriggen, D. Mazier, J. A. Robinson, G. Pluschke, Chem. Biol. 2007, 14, 577.

[31] a) C. Bisang, C. Weber, J. Inglis, C. A. Schiffer, W. F. Van Gunsteren, I. Jelesarov, H. R. Bosshard, J. A. Robinson, J. Am. Chem. Soc. 1995, 117, 7904; b) A. P. Nanzer, A. E. Torda, C. Bisang, C. Weber, J. A. Robinson, W. F. Van Gunsteren, J. Mol. Biol. 1997, 267, 1012.

32] a) R. Beeli, M. Steger, J. A. Robinson, Helv. Chim. Acta 1996, 79, 2235; b) C. Bisang, C. Weber, J. A. Robinson, Helv. Chim. Acta 1996, 79, 1825; c) F. Emery, C. Bisang, M. Favre, J. A. Robinson, J. Chem. Soc. Chem. Comm. 1996, 2155; d) M. E. Pfeifer, A. Linden, J. A. Robinson, Helv. Chim. Acta 1997, 80, 1513; e) C. Bisang, L. Jiang, E. Freund, F. Emery, C. Bauch, H. Matile, G. Pluschke, J. A. Robinson, J. Am. Chem. Soc. 1998, 120, 7439; f) M. E. Pfeifer, J. A. Robinson, J. Chem. Soc. Chem. Comm. 1998, 1977; g) M. E. Pfeifer, K. Moehle, A. Linden, J. A. Robinson, Helv. Chim. Acta 2000, 83, 444; h) R. Moreno, L. Jiang, K. Moehle, R. Zurbriggen, R. Glück, J. A. Robinson, G. Pluschke, ChemBioChem 2001, 2,838 ; i) B. Pfeiffer, E. Peduzzi, K. Moehle, R. Zurbriggen, R. Glück, G. Pluschke, J. A. Robinson, Angew. Chem. Int. Ed. 2003, 42, 2368.

[33] a) M. S. Müller, A. Renard, F. Boato, D. Vogel, M. Naegeli, R. Zurbriggen, J. A. Robinson, G. Pluschke, Infect. Immun. 2003, 71, 4749; 
b) A. Renard, M. Mueller, R. Zurbriggen, G. Pluschke, J. A. Robinson, Helv. Chim. Acta 2003, 86,3638 .

[34] a) S. James, K. Moehle, A. Renard, M. S Mueller, D. Vogel, R. Zurbriggen, G. Pluschke, J. A. Robinson, ChemBioChem 2006, 7, 1943; b) S. L. Okitsu, F. Boato, M. Mueller, D. B. Li, D. Vogel, N. Westerfield, R. Zurbriggen, J. A. Robinson, G. Pluschke, Peptides 2007, 28, 2051; c) M. Tamborrini, M. S. Mueller, S. A. Stoffel, N. Westerfeld, D. Vogel, F. Boato, R. Zurbriggen, J. A. Robinson, G. Pluschke, Malaria Journal 2009, 8, 314.

[35] a) S. L. Okitsu, O. Silvie, N. Westerfield, M Curcic, A. R. Kammer, M. S. Mueller, R. W. Sauerwein, J. A. Robinson, B. Genton, D. Mazier, R. Zurbriggen, G. Pluschke, PLoS One 2007, 2, e1278; b) S. L. Okitsu, M. S. Mueller, M. Amacker, D. Vogel, N. Westerfield, J. A. Robinson, R. Zurbriggen, G. Pluschke, Human Vaccines 2008, 4, 1; c) F. M. Thompson, D. W. Porter, S. L. Okitsu, N. Westerfeld, D. Vogel, S. Todryk, I. Poulton, S. Correa, C. Hutchings, T. Berthoud, S. Dunachie, L. Andrews, J. L. Williams, R. Sinden, S. C. Gilbert, G. Pluschke, R. Zurbriggen, A. V. S. Hill, Plos One 2008, 3, e0001493; d) P. G. Cech, T. Aebi, M. S. Abdallah, M. Mpina, E. B. Machunda, N. Westerfeld, S. A. Stoffel, R. Zurbriggen, G. Pluschke, M. Tanner, C. Daubenberger, B. Genton, S. Abdulla, Plos One 2011, 6, 11 .
[36] a) F. Boato, R. M. Thomas, A. Ghasparian, A. Freund-Renard, K. Moehle, J. A. Robinson, Angew. Chem. Int. Ed. 2007, 46, 9015; b) A. Ghasparian, T. Riedel, J. Koomullil, K. Moehle, C. Gorba, D. I. Svergun, A. W. Perriman, S. Mann, M. Tamborrini, G. Pluschke, J. A. Robinson, ChemBiochem 2011, 12, 100; c) A. W. Perriman, D. S. Williams, A. J. Jackson, I. Grillo, J. M. Koomullil, A. Ghasparian, J. A. Robinson, S. Mann, Small 2010, 6, 1191; d) T. Riedel, A. Ghasparian, K. Moehle, P. Rusert, A. Trkola, J. A. Robinson, ChemBiochem 2011, 12, 2829; e) R. Sharma, A. Ghasparian, J. A. Robinson, K. C. McCullough, PloS one 2012, 7, e43248.

[37] C. H. Bell, R. Pantophlet, A. Schiefner, L. A. Cavacini, R. L. Stanfield, D. R. Burton, I. A. Wilson, J. Mol. Biol. 2008, 375, 969.

[38] C. B. Wilen, J. C. Tilton, R. W. Doms, Cold Spring Harbor Persp. Med. 2012, 2, 13.

[39] A. Mann, N. Friedrich, A. Krarup, J. Weber, E. Stiegeler, B. Dreier, P. Pugach, M. Robbiani, T. Riedel, K. Moehle, J. A. Robinson, P. Rusert, A. Plückthun, A. Trkola, J. Virol. 2013, 87, 5868.

[40] a) L. T. Nguyen, E. F. Haney, H. J. Vogel, Trends Biotechnol. 2011, 29, 464; b) M. Wilmes, B. P. A. Cammue, H.-G. Sahl, K. Thevissen, Nat. Prod. Rep. 2011, 28, 1350; c) M. Pasupuleti, A. Schmidtchen, M. Malmsten, Crit. Rev. Biotechnol. 2012, 32, 143.
[41] a) S. C. Shankaramma, K. Moehle, S. James, J. W. Vrijbloed, D. Obrecht, J. A. Robinson, Chem. Commun. 2003, 1842; b) J. A. Robinson, S. C. Shankaramma, P. Jettera, U. Kienzl, R. A. Schwendener, J. W. Vrijbloed, D. Obrecht, Bioorg. Med. Chem. 2005, 13, 2055.

[42] J. Schmidt, K. Patora-Komisarska, K. Moehle, D. Obrecht, J. A. Robinson, Bioorg. Med. Chem. 2013, 21, 5806.

[43] a) M. P. Bos, V. Robert, J. Tommassen, Annu. Rev. Microbiol. 2007, 61, 191; b) N. Ruiz, D. Kahne, T. J. Silhavy, Nat. Rev. Microbiol. 2009, 7, 677; c) T. J. Silhavy, D. Kahne, S. Walker, Cold Spring Harb. Perspect. Biol. 2010, 2, a000414.

[44] E. Freinkman, S. S. Chng, D. Kahne, Proc. Natl. Acad. Sci. USA 2011, 108, 2486.

[45] a) N. Ruiz, S. S. Chng, A. Hiniker, D. Kahne, T. J. Silhavy, Proc. Nat. Acad. Sci. 2010, 107, 12245; b) S. S. Chng, M. Y. Xue, R. A. Garner, H. Kadokura, D. Boyd, J. Beckwith, D. Kahne, Science 2012, 337, 1665; c) C. L. Hagan, T. J. Silhavy, D. Kahne, Annu. Rev. Biochem. 2011, 80,189 ; d) S. Okuda, E. Freinkman, D. Kahne, Science 2012, 338, 1214.

[46] H. W. Boucher, G. H. Talbot, J. S. Bradley, J. E. Edwards, D. Gilbert, L. B. Rice, M. Scheld, B. Spellberg, J. Bartlett, Clin. Infect. Dis. 2009, 48, 1.

[47] D. T. Moir, T. J. Opperman, M. M. Butler, T. L. Bowlin, Curr. Opin. Pharmacol. 2012, 12, 535. 